\title{
Student Teamwork and Leadership in an Engineering Technical Writing Course
}

\section{Dr. Alyson Grace Eggleston, The Citadel}

Alyson G. Eggleston received her B.A. and M.A. in English with a focus on writing pedagogy and linguistics from Youngstown State University and her $\mathrm{PhD}$ in Linguistics from Purdue University. Her research and teaching interests are in technical and scientific writing pedagogy and the interaction of language and cognition. She is an Assistant Professor in the Department of English, Fine Arts, and Communications at The Citadel, The Military College of South Carolina.

\section{Dr. Robert J. Rabb P.E., The Citadel}

Robert Rabb is an associate professor and the Mechanical Engineering Program Director at The Citadel. He previously taught mechanical engineering at the United States Military Academy at West Point. He received his B.S. in Mechanical Engineering from the United States Military Academy and his M.S.E. and $\mathrm{PhD}$ in Mechanical Engineering from the University of Texas at Austin. His research and teaching interests are in mechatronics, regenerative power, and multidisciplinary engineering. 


\section{Student Teamwork and Leadership in an Engineering Technical Writing Course}

Technical proficiency is a desirable skill for engineers, but often is just one proficiency on a list of many required skills from employers. There is a growing need for engineers to have other professional skills: organization, communication, ability to function on a team, and leadership is critical for mastering these skills. Additionally, through course design, service learning, and mission, The Citadel emphasizes its leader development for ROTC and non-ROTC students. There is a formal, four-functional area leadership model that assesses leader development in multiple ways. Integrated in the leadership model are Leader Characteristics that describe a leader's actions. At the institution, professors assist in leader development by helping students mature their intellectual capacity to be leaders. As a focus of The Citadel's mission, leader development opportunities are reinforced at all levels of course design through critical thinking, communications, philosophical, theoretical, and analytical skills. In the leadership model, sophomores engage by learning the skills associated with direct leadership of individuals and small teams, and the management of specific administrative and logistical duties under close supervision - but with no intermediate leader between themselves and their subordinates. The School of Engineering at The Citadel took the initiative to collaborate with humanities faculty in the creation of a sophomore-level, multidisciplinary communications class that would lay the foundation for cross-disciplinary communications courses, while emphasizing team-driven Project-based Learning (PBL) and leadership development.

Collaboration between an English Department and three Engineering Departments in 2015 resulted in a sophomore-level Technical Writing and Communications course (TWC) to prepare future graduates with better communication skills. Anchored in (PBL), the course was designed and implemented with assignments allowing for the assessment of early leader development, as emphasized by the institution. The course required small teams to work on one hands-on, technical assignment, and several other group projects.

This paper discusses the implementation of a TWC (required of all engineering majors), which was subsequently expanded to assess teamwork and leader development for both the institution and specific programs. The paper also presents its institution-specific implementation, and current student success markers. Finally, this paper makes recommendations for embedding leader development opportunities within instructional design and peer assessment for the collective benefit of other students.

\section{Introduction}

Industry has recognized the need for engineers with multidisciplinary backgrounds, blurring the lines between discipline specific boundaries. Machines, materials, and processes constantly grow in complexity due to their purpose and flexibility as well as customer expectations. However, there is growing emphasis on engineers with "professional skills" as well. The National Academy of Engineering (NAE) in two reports [1], [2] stressed the need for engineers to possess leadership abilities. The former emphasized engineering graduates "must understand the principles of leadership and be able to practice them in growing proportions as their careers 
advance. Additionally, the latter report stated, "it is becoming increasingly recognized that it is important to introduce engineering activities, including team-based design projects ... early in the undergraduate experience." Curricular approaches that engage students in team exercises, in team design courses, and in courses that connect engineering design and solutions to real-world problems demonstrate the social relevance of engineering. However, the designs of these approaches and assessment of their effectiveness are not well documented, nor are tools to evaluate individual student performance [2].

Fundamental engineering, very applied and hands-on, is a stated need by industry. The ASME Vision 2030 [3] states that the problems that mechanical engineers work on often include elements of other engineering disciplines, require systems thinking in problem formulation and solution, and asserts that we must educate engineering students for a technological era of increased scope, scale, and complexity. However, this directive requires greater sophistication in curricular design, providing an interface between basic science and engineering at the systems level, and leadership for innovation. As industry relationships continue to inform curricular needs, expertise related to communication, innovation, and leadership will be required to a much larger degree in accelerated product development. These topics are typically not a significant part of the mechanical engineering curriculum.

According to ASCE [4], with the introduction of powerful computer technology and the trend toward increasing specialization, civil engineers' roles often limit their leadership opportunities. Civil engineers will have to command the multidisciplinary, multi-cultural, team-building, and leadership aspects of their work in order to lead and execute complex projects that involve many and varied stakeholders and meaningful collaboration.

Even with evidence cited in the vision papers from the NAE and specific disciplines, there still exists a lack of teaching and developing professional skills, including leadership, to engineering undergraduates. Some universities have developed leadership programs, minors, and certificates to address this need and close the gaps identified by others [5]. Some formal leadership programs have created "leadership labs" to create safe environments for students to practice leadership skills [6]. Other universities may employ these labs and embed them into existing courses.

Leadership informs both teamwork and communication, and the need for effective leadership and teamwork permeates through every engineering discipline. The accrediting board for engineering programs in the U.S. and many schools abroad is ABET, and they define student outcomes as "what students are expected to know and be able to do by the time of graduation." One of the Student Outcomes for the 2019-2020 cycle is "(5) an ability to function effectively on a team whose members together provide leadership, create a collaborative and inclusive environment, establish goals, plan tasks, and meet objectives" [7]. These strategic documents guide all engineering programs and are more than aspirational. They are meant to affect change, so implementing action to produce students with habitually effective leadership skills starts with the faculty. 


\section{Background}

Today's students are usually very comfortable with technology, have shorter attention spans, a lower threshold for boredom, resist memorization and homework and favor action to observation [8]. Learning styles of these students are visual and active rather than verbal. Incoming engineering students have interests and characteristics different from a decade ago. This age group places a high value on interaction, team activities and social networking [3]. Given the characteristic preferences of these students, educators are exploring different and innovative teaching strategies that effectively address students in terms that they easily recognize and comprehend. For effective instruction to follow, educators should accommodate the needs of the learner. Some have suggested that authentic learning requires the learner to communicate detailed understanding of a problem or issue rather than memorize sets of isolated facts, and must result in achievements that have relevance beyond the classroom [9].

One of the hardest things to do in our profession is to motivate and inspire students to learn. There are numerous examples of methods used to motivate students [10]. These various strategies include incorporating instructional behaviors, varying course structure, de-emphasizing grades, providing feedback, and emphasizing preparation, which provide many ideas on how to implement this new course. However, every teaching method has its advantages as well as its difficulties, so effective instruction uses multiple approaches. One noteworthy comment from Lang [11] was the conclusion that "comprehension lies outside of the classroom," meaning that students need to implement the traditional lecture material and move beyond basic classroom knowledge.

Caudron [12] advocated that educators consider five areas for improving teaching efficacy and some of these strategies are implemented in the recent improvement of this course:

1) Make learning experiential by engaging students in cooperative learning experiences.

2) Give students control of their learning.

3) Highlight key points since new learners are surfers and scanners rather than readers and viewers.

4) Motivate learning by engaging students in their own learning environment.

5) Challenge students to construct knowledge from their experiences.

\section{Course Overview}

Students at The Citdel take an institution-wide core curriculum in liberal arts, math and science that comprises much of the first four semesters. For engineering majors, the majority of the courses in the remaining four semesters builds on this foundation in the discipline-specific engineering. Engineering curricula are typically inflexible due to sequential learning in prerequisites for many courses and allow the fewest electives.

Addressing leader development in a busy engineering curriculum poses additional problems. The authors of this paper recognized the value of peer assessments to provide student feedback. All students at the institution receive leadership training and developmental opportunities for teamwork and leadership. With a predominately residence hall campus environment, students 
have additional exposure to each other in and out of the classroom. Peer perception can be very influential. With a high number of students as formal leaders in residence halls, ROTC, and other campus activities, they are also informal leaders in the classroom. At The Citadel all students take ROTC courses their first two years, but only those with ROTC scholarships going into the military will continue with ROTC courses their final two years. There are ROTC fulfillment courses for the non-ROTC students, but the leadership instruction in them varies. All students have exposure to leadership examples and experience by authoritative position, but most are direct admits from high school with little corporate or industry leadership knowledge. However, all are assessed by the leadership model developed at the school. In fact, The Citadel highlights the leadership activities and teamwork skills developed here in and out of the classroom as an institutional hallmark. The authors wanted to assess student leadership skills in a humanities course that serves engineering students and determine if there existed further opportunity to develop leadership skills in the classroom.

The approach taken by the Technical Writing Course and the School of Engineering begins with designing a multi-layered and dynamic educational experience for the students. The experience starts with traditional writing courses as part of the General Education Model at the institution. During sophomore year, engineering students take Technical Writing and Communications where they are introduced to the fundamental principles of technical writing and use a projectbased learning model. Much of the general education requirements for engineering students at the institution occurs in the first two years. Engineering curricula are increasingly moving toward an earlier introduction of engineering content for entering students. Eli Fromm of Drexel University was one of the earliest curriculum innovators to introduce engineering activities early in the curriculum, integrating faculty across campus [2]. Similarly, a team consisting of faculty members from across this institution developed a Technical Writing Course to promote communication. However, the faculty discovered an opportunity to develop and assess leadership and teamwork skills in the same course.

Informed by these discussions, the technical writing and communication course discussed here uses a Project-based Learning (PBL) approach to provide sophomore-level exposure and mastery of the following three content categories:

1) Technical Writing Conventions

a. discuss and evaluate authentic documents for technical style

b. situational and audience awareness

c. potential for security vulnerabilities and liabilities

d. possibilities for plagiarism and copyright infringement

2) Project Management Tools

a. working familiarity with software applications that support the process of producing technical documents

3) Authentic Documents for informational and persuasive writing and communication

a. requests for proposals (RFPs)

b. proposals

c. presentations and verbal briefs

d. posters 
At all stages of producing the four major course projects, students are prompted to apply their developing sense of technical style and preparation, while also leveraging the software applications that most suit the challenges they encounter.

The course recently implemented a team exercise with iFixit [13], a wiki-based site that teaches people how to repair electronic and electromechanical devices rather than dispose of them.

Student teams of four had to troubleshoot an unserviceable item (laptop, kitchen appliance, smart phone, etc.), repair it, and create a repair manual for the device. Figure 1 shows a student team engaged with the iFixit project and delegating work tasks. iFixit allows individuals to share their technical knowledge with the rest of the world. As part of the project, teams documented their written procedures with pictures. Their submissions were graded by the instructor, who is iFixit certified and trained, and by a team of outside evaluators at iFixit.

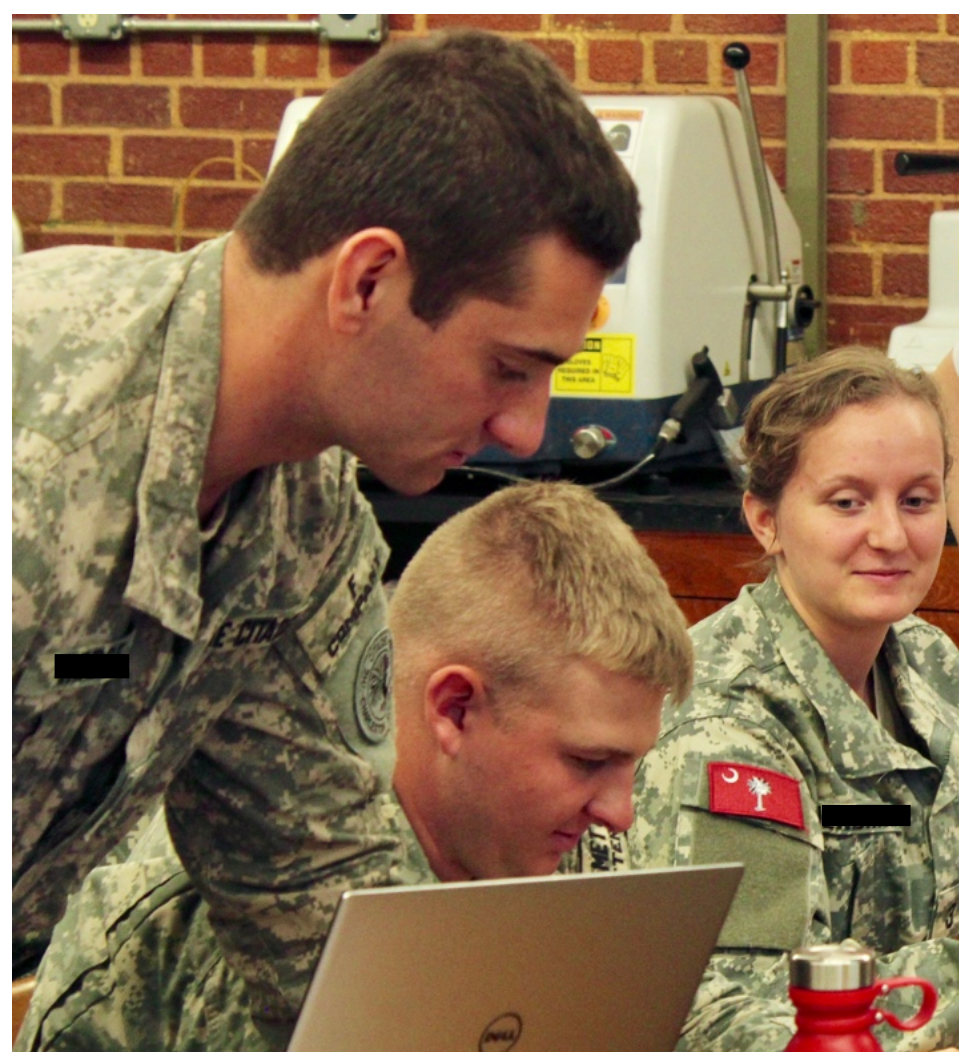

Figure 1: Student Teamwork and iFixit Project

\section{Research Questions}

One goal of the collaborative work between the Technical Writing Course and the School of Engineering is to identify best practices to support the leadership assessment goals of The Citadel and the engineering disciplines. Since all students are trained periodically on the institution's leadership model, the instructor could focus more on content and assessment rather than explaining the leadership model and requirements. With a readily available leadership assessment tool, two questions the instructor wanted to answer include: 
1) Can students be objective and constructive through peer assessments to make a positive difference in team members' leadership skills?

2) Can the institution's new leadership assessment tool be used in a variety of courses?

The leadership assessment tool, described later in this paper, allowed the instructor to contextualize inconsistencies if necessary.

\section{Methodology}

The Citadel's Leadership Center developed an entire leadership model and program for all students [14]. All students must learn and should internalize the leadership model over four years. Their instruction includes case studies, formal leadership classes and seminars. Within the model are individual leadership characteristics, and all students are assessed on their leader development against these characteristics.

The Comprehensive Assessment of Team Member Effectiveness (CATME) tools from Purdue University for peer evaluation uses a normalized average score for each student [15]. CATME rounds scores $0.95-1.00$ up to 1.00 and limits scores above 1.05 at that value. There is some uncertainty in the peer scores. The School of Engineering was required to assess leadership based on the seven leadership characteristics identified at The Citadel's Leadership Center (Table 1). One department was using CATME to assess individual performance and contribution in the senior capstone. All of the engineering departments implemented a modified CATME survey to assess these seven leadership principles.

The TWC instructor implemented the survey as well for leadership and teamwork assessment. The following assessment first looked at the normalized scores of the individuals with and without self-assessment. This gave the instructor and students a broad picture of group dynamics and overall idea of who was a performer and those that needed to improve. The assessment then went further and looked at the individual leadership characteristics produced by the institution's leadership center in order to target specific areas of improvement for individuals.

The assessment method included student survey data early (1 week) in a hands-on iFixit device repair project and after completion of the project ( 5 weeks). The students completed a sevenquestion survey on the Characteristics of Principled Leaders, rating each team member including $\mathrm{him} /$ herself on all seven characteristics. All students were familiar with the Characteristics of Principled Leaders, and shorter definitions were included with each characteristic to remind students of the characteristic. Table 1 shows part of the survey without columns to the right for every team member to provide ratings.

Table 1: Characteristics of Principled Leaders

\begin{tabular}{|l|l|}
\hline & Leadership Attribute \\
\hline 1. & $\underline{\text { Leads with humility; creates conditions for the team to succeed as a whole. }}$ \\
\hline
\end{tabular}




\begin{tabular}{|c|l|}
\hline 2. & $\begin{array}{l}\text { Embraces a true, authentic self; develops and leads according to a principle-based } \\
\text { leadership philosophy. }\end{array}$ \\
\hline 3. & $\begin{array}{l}\text { Acts and speaks with courage; performs critical leadership functions to overcome } \\
\text { resistance leading to positive change and outcomes. }\end{array}$ \\
\hline 4. & $\begin{array}{l}\text { Develops and values people and resources; exhibits characteristics of a global citizen } \\
\text { and displays desire to openly serve. }\end{array}$ \\
\hline 5. & $\begin{array}{l}\text { Empowers and holds others accountable; delegates authority, allows others to } \\
\text { optimize unique abilities leading to beneficial results of the collective team. }\end{array}$ \\
\hline 6. & $\begin{array}{l}\text { Respect others by building trust and learning from mistakes; demonstrates } \\
\text { inclusive leadership traits that embraces diversity, creates security, opportunity and } \\
\text { fulfillment. }\end{array}$ \\
\hline 7. & Serve others before self; expands outreach and engagement with broader community. \\
\hline
\end{tabular}

The data from 43 students was included in this study. A standard five-level Likert Scale (Table 2) with descriptors provided for each rating was used to assess the level of agreement or disagreement for the leadership attributes for each team member. The rating scale is a normal set of responses used at The Citadel for student surveys. Students and faculty alike are familiar with the same standard set of responses and their interpretation.

Table 2: Assessment Scale

\begin{tabular}{|c|c|c|c|c|}
\hline $\begin{array}{c}\text { Strongly } \\
\text { Disagree }\end{array}$ & Disagree & Neutral & Agree & $\begin{array}{c}\text { Strongly } \\
\text { Agree }\end{array}$ \\
\hline 1 & 2 & 3 & 4 & 5 \\
\hline
\end{tabular}

This leadership model and identified attributes are part of the institution-wide leader development and school brand [14]. It was validated and developed over several years through the Leadership Department and in consultation with military and corporate leaders. Students learn and experience the leadership model over four years. At the time of this survey, all students had at least one or more years of the model as part of their formal leadership education. Students use the attributes to rate peers in traditional leadership roles (student clubs, ROTC, dorm cadre, etc.).

\section{Results}

The 43 students were divided into teams of four or five individuals and assigned a device that needed a repair. Each team scored their teammates using the questions from Table 1 using the Likert Scale. Results were averaged within the four or five-person teams with a team average and an individual average for each of the seven leadership characteristics. This was done early into the project (week one) and after completion (week five). The averages for the seven leadership characteristics were also calculated at weeks one and five. 
The authors originally employed the leadership assessment to gather baseline information on individuals for a longitudinal study. However, students were receptive and responsive to peer assessment. This paper includes a short-term analysis of the data for teamwork. The longitudinal results for leader development will require more time and coordination with other faculty.

The first research question examined by this paper is to determine if students can be objective and constructive through peer assessments to make a positive difference in team members' leadership skills. It is important to point out that students enrolled in the sophomore level Technical Writing Course are mixed with students from four different engineering majors and two science majors. Additionally, these students are primarily residence-only students and share many campus activities: dorm life, dining facility meals, etc., and have increased contact with each other.

A quick comparison of the averaged individual score at week one and five indicates over 37.5\% of the students had improvements in their overall peer leadership assessments. Approximately $10 \%$ had significant improvements - changing from a team liability with a normalized score less than 0.95 to a team asset or leader with a normalized score greater than 1.05. Some students admitted that they modified their behavior as a result of the feedback provided by their teammates. Although this is not a majority of the class, the significance is that peer expectations and early feedback can modify individual performance.

Figure 2 below shows a sample student with peer assessment for each leadership characteristic. Data includes:

1) Individual average for week one

2) Team average for week one

3) Individual average for week five

4) Team average for week five

Also included in the far-right column are the overall normalized averages for all seven leadership characteristics for the student and his or her team, similar to CATME. Results were normalized, so a 1.00 indicates an average or expected rating based on all seven leadership attributes. Any score above 1.00 indicates the individual is performing better than average in the leadership characteristics. Any score below 1.00 shows the individual is performing worse than expected. At week one, his normalized average was 0.90 and improved to 1.10 by week five.

It is clear that Student ' $D$ ' was performing below average in his team for all seven areas at week one. At the end of the team project, he clearly improved and exceeded the team average in all seven areas. It is important to note that the overall team average (average of all seven leadership characteristics) was consistent at week one and week five with only a change of 0.05 on the 5point scale (1\%). However, Student 'D's' average increased 0.61 on the 5 point scale (from 4.14 to 4.75$)$.

Had this early feedback and opportunity for self-improvement not occurred, there was the potential for Student ' $D$ ' to think his early teamwork and involvement was acceptable. In other 
cases and projects, this has led to mismatched expectations for grade and final peer assessment. The early feedback has the ability to mitigate and reduce the number of these issues.

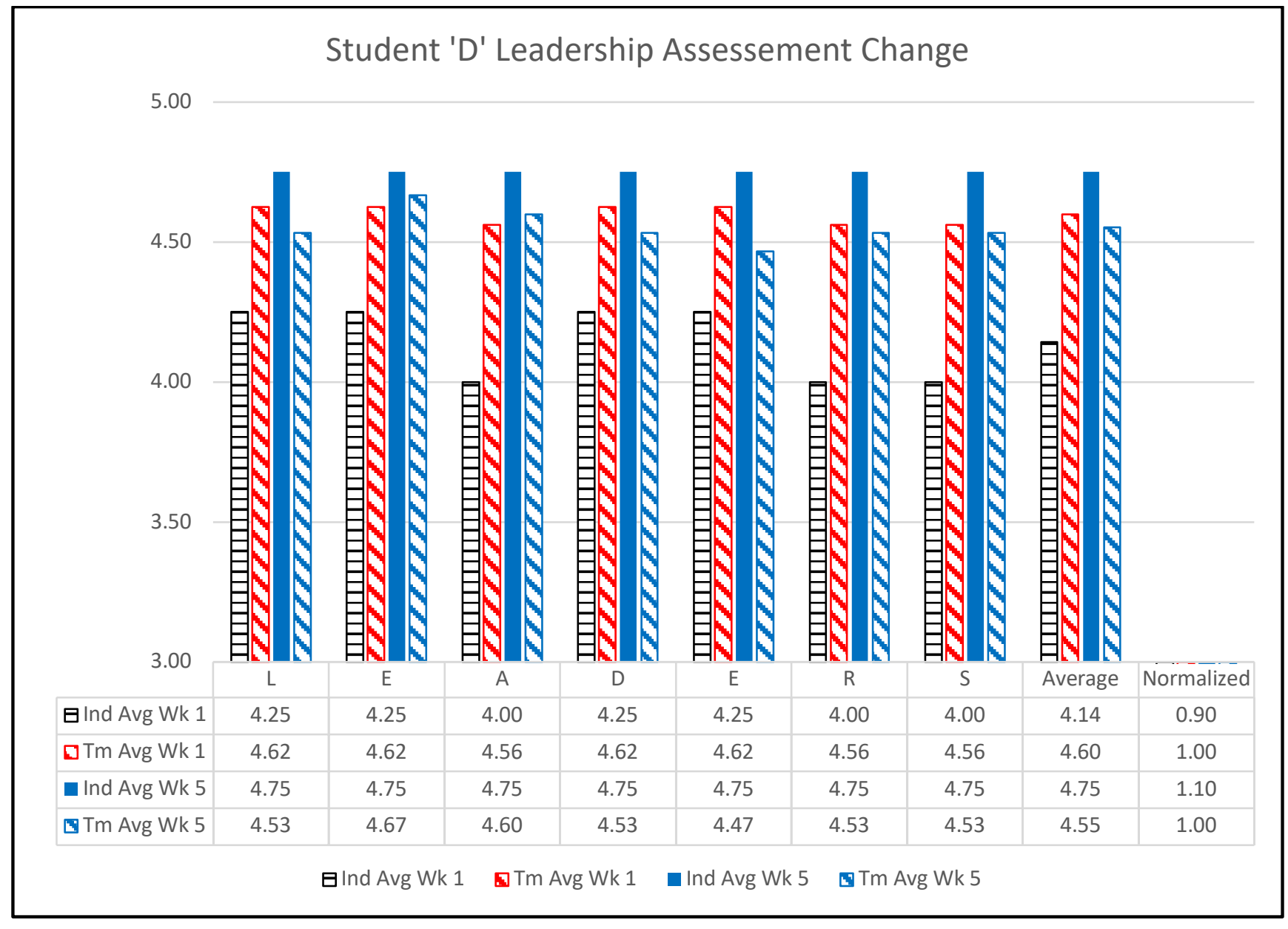

Figure 2: Student 'D’ Leadership Assessment

This positive improvement in Student ' $D$ ' was offset slightly by lower assessments of other teammates. However, the other teammates' assessments on week one and week five were relatively stable on the 5 point Likert Scale. On the normalized scale similar to CATME, the instructor used the true normalized assessments for each student and did not round or cap any values. For Student ' $D$ ' the normalized score at week one was 0.91 and at the end of the project, it was 1.098. Again, a normalized score of 1.00 indicates average and performing at team norms. This student was a below the team's normalized score early in the project, and was exceeding the team's normalized score at the end of the project. By looking at the individual leadership characteristics on a scaled score, and the individual's aggregate score on a normalized scale, this is an indication of the consistency of the assessment.

Leadership assessments can have near-term positive opportunities for learners. This peer feedback uses social comparison. Social comparison theory suggests that we make better assessments of others and ourselves when we make relative comparisons. Relative comparisons involve comparing several people and ourselves at the same time when providing ratings [16]. 
When presented with this information early in the semester, the instructor can counsel the student with this aggregated information and specific areas to improve. Student D wanted to improve as a team member (internal motivation), had the tools to improve (leadership model and attributes), and the information from the instructor on specific areas (direction).

The second research question concerns how well can the institution's new leadership assessment tool be used in a variety of courses - how versatile is it? Although originally developed as an overall assessment tool for traditional student leader development, the survey has been implemented in engineering senior design courses. This paper shows that it can be employed earlier in the curriculum as part of a project-based learning event in the technical writing and communications course. It is not evident to the authors how much formal leadership education is necessary so students can provide fair constructive feedback to their peers. However, the institutionally validated model described here appears to be useful at least at the sophomore level.

Although there is a fair amount of content and requirements in a technical writing course, leadership assessment and development can occur, which in turn, support the outcomes of the multiple engineering disciplines, and mission of the institution. Teamwork assessment for ABET by faculty occurs later in the curriculum, but reinforcing the leadership principles and fostering teamwork outside of the major is a novel approach. Any reinforcement of teamwork and leadership for undergraduates scaffolds and builds the professional skills the students will need later in the senior capstone and once they graduate.

This assessment tool is general enough to be used on traditional students whether or not they will serve in the military via ROTC. Student D above was a traditional student, and developed some leadership proficiency when counseled with objective data. Students, assessed on the same standards and criteria, show that they can excel in the professional skills, such as leadership and teamwork, sought by many engineering disciplines, even in non-engineering courses.

\section{Conclusions and Future Work}

This paper describes recent changes in a project-based Technical Writing Course where leader development and assessment occurred. This small deployment of a modified CATME survey has shown some promising results that merit further investigation. The authors plan to use the modified assessment tool in future offerings of multidisciplinary courses, especially in the technical writing and communications course. Here, engineering students from four different majors can provide early peer feedback and improve their effectiveness. Using a proven leader development model and assessment tool in a technical writing course is novel. Using a tool for early assessment gives team members a voice. This drives student engagement, as they become invested in the projects, reinforcing the idea that students must continually strive to update their skills throughout their careers. There are many opportunities to support the institution's goals and improve student professional skills. Not everything needs to be accomplished within a particular program. Incorporating leadership in an engineering curriculum is not easy, but programs should realize the benefits of coordination with non-engineering faculty and nesting assessment with the goals of the institution. Leadership development at The Citadel where students and faculty are involved are successful due to shared goals to improve and collaborate. 
As the US, and the world, need more engineers, one way to make them better is to hone their leadership skills in the classroom and prepare them for the future.

\section{References}

[1] National Academy of Engineering (NAE). (2004). The engineer of 2020: Visions of engineering in the new century, Washington, DC: National Academies Press.

[2] National Academy of Engineering (NAE). (2005). Educating the Engineer of 2020: Adapting engineering education to the new century, Washington, DC: National Academies Press.

[3] "ASME Vision 2030: Creating the Future of Mechanical Engineering Education," Executive Summary, ASME Board on Education, go.asme.org/v2030, September 2012.

[4] American Society of Civil Engineers, "Achieving the Vision for Civil Engineering in 2025," ASCE, Reston, VA, August 2009.

[5] R. Graham, E. Crawley, and B. Mendelsohn, Engineering leadership education: A snapshot of international good practice. Cambridge, MA: Bernard M. Gordon MIT Leadership Program, 2009.

[6] S. Pitts, S. McGonagle, S. Klosterman, Developing Engineering Leaders using Engineering Leadership Capabilities and Leadership Labs, Proceedings of ASEE Conference, Atlanta, GA June 22-25, 2013.

[7] ABET, retrieved from http://www.abet.org.

[8] A. Litten and B. Lindsay, "Teaching and learning from Generation Y". A presentation for ACRL New England annual program; June 1, 2001, Brandeis University.

[9] B. Brown, "New learning strategies for generation X”. ERIC Digest, 1997, p. 184.

[10] B. Davis, Tools for Teaching, Jossey-Bass Publishers, San Francisco, CA, 1993.

[11] J. Lang, "Beyond Lecturing” The Chronicle of Higher Learning, September 29, 2006.

[12] S. Caudron, "Can Generation Xers be Trained?" Training and Development, vol 3, pp. 2024, 1997.

[13] https://www.ifixit.com/[Online] [Accessed Mar 14, 2019].

[14] http://krausecenter.citadel.edu/.

[15] M. Loughry, M. Ohland, and D. Moore, "Development of a Theory-Based Assessment of Team Member Effectiveness," Educational and Psychological Measurement, vol. 67 (3), pp. 505-524, 2007.

[16] T. O'Neil, et al, Peer Ratings and Intentions to Change: Adopting the CATME to Explore Outcomes of Peer Ratings, Proceedings of the ASEE Annual Conference \& Exposition 2015, Seattle, WA, June 14-17, 2015. 